\title{
Power of "WhatsApp Chaupal" on the Academic Enactment of Graduate Students of Lahore- A Review Paper
}

\author{
Mudassar Riaz Bhatti ${ }^{*}$, Ayesha Nawz ${ }^{2}$, Abdul Wajid Khan ${ }^{3}$, Ghulam Safdar ${ }^{4}$ \\ ${ }^{1}$ Ph.D Scholar, School of Journalism and Communications, Shaanxi normal University Xia'n, China \\ ${ }^{2}$ Mphil Scholar, Department of Mass communication, Beacon house National University, Lahore. Pakistan \\ ${ }^{3 A}$ ssistant Professor, Assistant Professor, Department of Media Studies, the Islamia University Bahawalpur, \\ Pakistan \\ ${ }^{4}$ PhD Scholar, Department of Media Studies, the Islamia University of Bahawalpur, Pakistan
}

*Corresponding Author: Mudassar Riaz Bhatti, Ph.D Scholar, School of Journalism and Communications, Shaanxi normal Universitv Xia'n. China

\begin{abstract}
This study finds out the effects of using WhatsApp as a teaching method to improve writing, speaking, listening, reading and critical skills of postgraduate students of Lahore, Pakistan. An experimental research approach was employed in which 'within-subject experimental design' was selected. $n=25$ female students enrolled in the first semester of master's in mass communication from media studies department of a private university were selected through purposive sampling. Participants were first taught for two hours in the classroom followed by a one-hour face-to-face learning session entitled traditional Chaupal. The same students were taught during the second semester in the classroom for two hours along with an additional hour of learning session was given to them through the WhatsApp group with the name of digital Chaupal. Data was collected through a test to evaluate their writing, reading, listening, speaking and critical skills after both sessions. Findings show that the students performed better after using WhatsApp as a teaching method. Teaching through WhatsApp becomes the best-preferred teaching aid, which can be supplemented by classroom learning for better results.
\end{abstract}

Keywords: WhatsApp, teaching, students, interpersonal communication, Chaupal, performance, graduate

\section{INTRODUCTION}

Nowadays teachers are using interesting teaching methods and techniques such as use of audio-visual aids to enhance the minds and the capabilities of students. Ghavifekr and Rosdy (2015) mentioned that technology-based learning helps students to share and express their ideas in logical and critical manner. Keeping in mind the recent developments and rapid change in the information and technology sector, instructors are taking the help of technology to make their teaching method interesting as well as effective. The modern approach to teaching is basically designed to develop the decision making and critical thinking ability of students. Traditional method of teaching revolves around teacher however modern or constructivist approach to teaching is centered on students.

Traditional class room method of teaching is also effective in improving academic grades and skills of students. Though face to face to learning is traditional method of teaching but still it is considered important in improving confidence of students. Established educational institutes and universities are trying to update themselves with the digital transformation of the world. With the help of innovative technologies, teachers are trying their best to engage students with them. There are so many teaching tools which are being used by instructors like power point slides, charts etc. however teachers are restricted to use it in the boundary of the classroom to maintain decorum and discipline of university. Face to face learning is losing its charm with the passage of time. The advent of technology has badly affected face to face communication. (Drago, 2015). With the help of different networking applications, one can easily communicate with people living miles away within seconds. Nowadays smarts phones are taking the world by storm. You can easily find people living without basic necessities of life, but it would be difficult to find someone without access to smart phone. Furthermore, the emergence of different smart phone applications is affecting almost every aspect of our lives. In this regard, WhatsApp is the most famous and unique networking application through 
which one can send text, audio and video message to any part of the world without any additional cost. WhatsApp application was launched by JanKoum and Brian Acton and it's been ten years since WhatsApp was first launched in the year 2009. There are many interesting features which makes it one of the most popular messaging apps among students. It has been used as a teaching tool to refine writing skills of students (Awada, 2016; Fattah, 2015; Justina, 2016), to increase understanding between teachers and students (Elhay\& Hershkovitz, 2019; Najafi\&Tridane, 2015; Rosenberg \&Asterhan, 2018), to improve academic performance of students (Amry, 2014; Elhay\& Hershkovitz, 2019).

In this context, WhatsApp application is gradually making its place among students. Different national and international academic institutions are using WhatsApp application for academic and administrative purpose. Usually they construct WhatsApp group of each class to keep students update regarding timetable, syllabus and other stuff. That WhatsApp group acts as a digital Chaupal where people can connect and share their experiences with each other.

However, amid all these benefits, we cannot neglect the negative effects of WhatsApp on academic performance and skills of students. Studies suggest that WhatsApp has negative effect on writing skill of students. Students distort language on WhatsApp by using different kinds of shortcuts and contractions. (Salem, 2013; Yeboah\&Ewur, 2014). Teachers are also apt to be irritated by flood of irrelevant and illogical messages. (Bouhnik, Deshen, \&Gan, 2014; Doering, Cynthia, George, \& Nichols-Besel, 2008). Furthermore, blue tick and last seen feature of WhatsApp let user know about the last activity of the respondent. It becomes one of the main reasons behind disagreements and misunderstand ings between students when respondent don't reply back to WhatsApp message after reading them. (Blabst\&Diefenbach, 2017)

The use of WhatsApp in Pakistan is increasing with the passage of time. Hussain, Mahesar, Shah, and Memon (2017) demonstrated that 65\% students use WhatsApp application daily in Pakistan and check their WhatsApp for more than four times in a single day. It's being used by journalists in Pakistan to share news at fastest pace (Azeema\&Nazuk, 2017). Likewise, WhatsApp is being used in schools, colleges and universities by students of all ages. Students use WhatsApp to communicate effectively with their friends, colleagues and family member on regular basis.

\subsection{Statement of the Problem}

Traditional teaching method require teachers to address students in classroom in the form of lecture. Students mostly learn their lessons through memorization and recitation techniques which is definitely affecting their ability to think in a negative manner. Liu and Long (2014) asserts the fact that traditional teaching method in classroom is mostly centered around teacher and they hardly acknowledge the individual personality of student.

As the world is heading towards the end of 21 st century, people are shifting towards technology and replacing old model of communication with the latest ones. In this regard, it is essential to update our educational system and teaching methods. The use of networking applications in the academic and administrative sector in order to enhance the mental capabilities and working abilities of the staff and students will contribute in the economic and social development of society. The effectiveness and popularity of WhatsApp application in developed and developing states is beyond question. In this regard an attempt has been made to determine how well this networking application can help students to improve their academic grades as well as their cognitive and creative skills.

Keeping in mind the popularity of mobile phones among youth across the globe, it's important to highlight its positive role in the context of current research. The question arises, "Do students prefer learning through WhatsApp over traditional method of learning through blackboard? Bere (2012) states that traditional method of learning through blackboard which is also known as e- thutho is gradually losing its importance among students and they prefer learning through WhatsApp messaging application.

A study was conducted in Taibah University of Medina, Saudi Arabia to explore the effects of using WhatsApp application as a teaching tool on the academic achievements and attitudes of students. An experimental design was employed in this study. It draws a comparison between face to face and WhatsApp learning. A total number of 30 students participated in the study. The findings show that 
there is a significant difference in the attitudes and behavior of experimental group in comparison with the control group (Amry, 2014).

In order to evaluate the significance of WhatsApp application in academic institutions, an online questionnaire was constructed by Ahad and Lim (2014) to evaluate the performance of students enrolled in undergraduate program of Brunei Darussalam University. The findings show that WhatsApp is being used among students to share and discuss academic matters and notes. The respondents also mentioned that WhatsApp plays a major role in strengthening interpersonal relationship with family and friends. However, some of the disadvantages mentioned by respondents include prevalence of unauthentic data, distraction to studies and a definite increase in the expectation level of users. (Ahad\& Lim, 2014). Here question arises that how can WhatsApp distract people from studies? Yeboah and Ewur (2014) asserts that spending a lot of time on WhatsApp application may distract students from studying. Students continuously use WhatsApp for entertainment purpose and so they do not concentrate on the ongoing lecture. Furthermore, they also mentioned that it affects their ability to construct complete sentence.

A study was conducted by Plana et al. (2013) in Spain. The main objective of the study was to find out the effectiveness and drawbacks of using WhatsApp application in improving reading skills of students. The major findings of the study show that respondents are more willing to read after using WhatsApp as a teaching tool. It also resulted in increasing their confidence level.

The social networking applications brings us closer. It allows people to communicate with their family, friends and colleagues without any additional cost. It provides them an avenue where they can easily share their sentiments and feelings. However, just as coin has both sides, it has also some drawbacks. To mention one of them, the increasing use of WhatsApp destroys spellings and grammatical construction of a basic sentence. (Yeboah\&Ewur, 2014)

However, a study was conducted in UK to analyze the way WhatsApp is being used among different professionals. The main objective of the study was to explore the relationship developed through the short narratives shared on WhatsApp. A total number of 20 professionals participated in the study. Semi structured interviews were conducted from them. The findings show that WhatsApp application provides professionals a kind of digital platform on which they can develop, maintain and improve their relationship with other people (O'Hara, Massimi, Harper, Rubens, \& Morris, 2014). In order to see the comfort level between the interactions of students and teachers, Lauricella and Kay (2013) asserts that WhatsApp improves the communication and understanding level between students who belongs to different economic backgrounds. It also creates a bond between teachers and students.

Bouhnik et al. (2014) conducted 12 semi structured interviews with the teachers in Israel. The main objective of the study was to find out the reasons behind using WhatsApp application. The results show that the application of WhatsApp is being used for discussion and learning purpose. It's being used to expand knowledge with each other. The fastest mode of communication on WhatsApp provides them an opportunity to reach people in single click. The easy mode of communication is helpful in saving time. It also improves relationship among students and teachers. An analysis of WhatsApp group was also done by Bouhnik et al. (2014) in order to figure out the factors behind using WhatsApp groups. One of the main advantages of using WhatsApp group is learning outside the boundary of classroom. One can communicate with teacher/student after class hours as well. There were also some disadvantages. The flood of irrelevant and informal messages on WhatsApp creates a kind of disturbance in teachers and student's life which can waste a lot of time.

A research was conducted to evaluate the interaction between teachers and students through instant and text messaging applications. A total number of 75 undergraduate students participated in the study. Online survey form was administered to determine the interpersonal relationship among students and teachers. The findings disclose that students feel comfortable to communicate with teachers and their peer group through instant messaging applications. They were of view that WhatsApp is easy to use and it saves a lot of time. (Lauricella\& Kay, 2013).

In literature review, an attempt has been made to look at the studies related to effects and importanceofWhatsAppineducationalsector. Tothebestofourknowledgeit'sinterestingtonote no formal study has yet been done on the use of WhatsApp as a teaching tool in Pakistan to explore the possibilities of using WhatsApp for teaching. The studies mentioned the advantages and 
disadvantages of using WhatsApp in educational sector. Previous research studies did not highlight how close WhatsApp group can be used in local socio-cultural setting in Pakistan. Thus, this research will provide an original contribution to existing knowledge on the subject.

Traditionally, people used to sit together for communication specifically in rural areas (which was known as Chaupal in the rural areas of North India and Pakistan) after long tiring day in order to sharetheirproblems, opinionsandvision.Livinginafastpaceworldwhereonedoesn'tevenhave time for themselves, technology brought us together. WhatsApp provides us a form of 'Digital Chaupal' where one can not only communicate with each other, but it also provides a venue where our new generation can improve their creative and cognitive skills by communicating with their mentors and teachers regarding their subject. Research into finding the impact of WhatsApp for academic purpose is sparse in Pakistani context. Hence, it's important to study the phenomenon in Pakistani context to understand the dynamics and role of WhatsApp as a teaching tool.

\subsection{Objective}

This study is an attempt to explore utilizing WhatsApp application in the academic sectors of Pakistan to improve critical and cognitive skills of students. The aim of the research is to analyze the effects of employing WhatsApp messaging application as a teaching tool on the reading, writing, speaking, listening and critical skills of graduate students of Karachi.

The review of literature indicates mixed opinions about the effects and content of WhatsApp application on students and professionals' i.e. affecting academic performances positively and negatively, loosening as well as strengthening bonds between teachers and students, helping as well as distracting from studies, most of the literature suggests that WhatsApp application is playing an important role in connecting and helping students. Respectively, the analyses conducted in most of the studies do not warrant conclusions about the nature of ongoing content being shared by students who are using WhatsApp. The togetherness and intimacy enacted through these conversations has a history and an ongoing trajectory into the future in Pakistan which needs to be studied thoroughly. All these researches suggest that there is a need for further research preferably longitudinal studies with experimental intervention to determine the effects of WhatsApp application specially in academic sectors.

\subsection{Hypothesis}

H1: There is a statistically significant difference between the Chaupal (face to face learning) and digital Chaupal (WhatsApp group) regarding the achievement test scores of students.

According to the knowledge claim of the researchers, it is predicted that digital Chaupal will have a positive effect on the academic performance of students.

\section{METHOD}

Case study based Experimental research approach was carried out in order to evaluate the effects of using WhatsApp as a teaching tool on the academic performance and skills of students. Within subject experimental design was used in this study. Sample includes 25 female students from one of the private universities of Pakistan who were all enrolled in the first semester of master's program in the department of Media and Communication in the year of 2018 from Feb to July (3 months for each semester). Two different subjects were taught in the first and second semester. They had no prior subject knowledge which was assessed through a pre-test. Data was collected through classroom and WhatsApp group to ensure reliability. Closed group was maintained to avoid subjective interpretation. Data was validated by ethical consent taken from the students before and after participation. It should also be noted that students were studying in traditional Chaupal when the experimental group was studying under digital Chaupal to exclude extraneous variables.

In this research design students were first tested under controlled in the first semester. After first semester, same group of students were tested under experimental condition. An attempt was made to control the extraneous variables in the study. In this regard, pre-test was taken to test the subject knowledge before both semesters in order to configure the critical and cognitive skills of students. They got almost similar scores in pre-test which shows that their subject knowledge was almost same. Both groups were tested in the same environment and setting as similar as possible. Most of the students belong to similar age group. Students were taught for same number of hours. 
In the beginning of the semester, students were exposed to face to face learning in classroom for two hours. Afterwards, another teaching session entitled 'CHAUPAL' (face to face learning) was introduced in which students were taught in the same classroom for additional one hour. In that Chaupal, Students could discuss their queries related subject. The researcher as subject teacher was also part of the Chaupal to maintain decorum of the class. No one was allowed to use any kind of smart phone or texting application in the classroom. The students had already WhatsApp accounts on their numbers. In the second semester, the instructor made a WhatsApp group entitled 'DIGITALCHAUPAL' and introduced it to students as a new platform of learning subject based stuff.

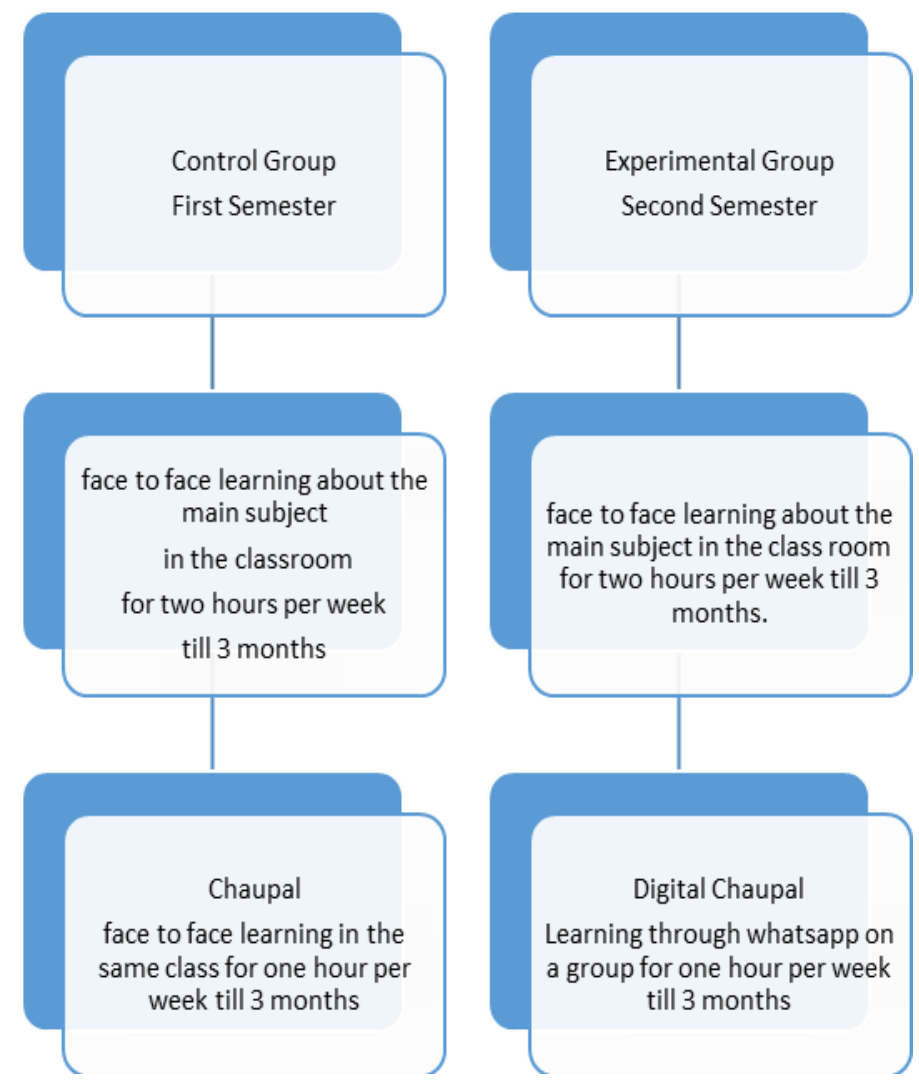

Chartno.1.1. Flow chart of Data Analysis Process

The instrument which was employed in this study to collect data was test (comprised of 20 marks) to see how students communicate and respond under controlled and treatment condition. The test was designed to evaluate the reading, writing, speaking, listening and critical skills of students. Three subject teachers were asked to check the content validity of written test to avoid biasness. They were asked to give their feedback on five points rating scale about how well the written test measures the construct. A written informed consent was obtained from the students before their participation. Students were free to participate in that WhatsApp group. There was no pressure on them from teacher for the participation. It was made clear that the content shared on digital Chaupal (WhatsApp group) will be only.

The overall time allotted for test was about 2 and half hours (30 minutes per task). It was divided under following main sections:

Table1. Teaching Method and Evaluation Criteria

\begin{tabular}{|c|c|c|c|c|c|c|c|}
\hline \multicolumn{2}{|c|}{\begin{tabular}{|l|l|} 
Ouestio & Main \\
\end{tabular}} & \multicolumn{2}{|c|}{ Teaching Method } & \multicolumn{2}{|l|}{ Task } & \multicolumn{2}{|c|}{ Evaluation Criteria } \\
\hline & & Face to Face & WhatsApp & $\begin{array}{l}\text { Face } \\
\text { to Face }\end{array}$ & $\begin{array}{l}\text { Whats } \\
\text { App }\end{array}$ & $\begin{array}{l}\text { Face } \\
\text { to Face }\end{array}$ & $\begin{array}{l}\text { WhatsA } \\
\text { pp }\end{array}$ \\
\hline $1-5$ & Reading & Newspaper & $\begin{array}{l}\text { E-paper of } \\
\text { Newspaper }\end{array}$ & $\begin{array}{l}\text { Readin } \\
\text { Compr }\end{array}$ & ion & $\begin{array}{l}\text { Reading } \\
\text { Underst } \\
\text { Content } \\
\text { Words I } \\
\text { Correct }\end{array}$ & $\begin{array}{l}\text { ed, } \\
\text { g } \\
\text { nber of }\end{array}$ \\
\hline
\end{tabular}


Power of "WhatsApp Chaupal" on the Academic Enactment of Graduate Students of Lahore- A Review Paper

\begin{tabular}{|c|c|c|c|c|c|}
\hline $6-10$ & Speaking & Audio Visual Aids & Microphone & Discussing News & $\begin{array}{|lr|}\text { Intonation \& } & \text { Stress, } \\
\text { Relevance } & \text { and } \\
\text { Completeness } & \text { of } \\
\text { Content, } & \text { Talking } \\
\text { without } & \text { Pauses, } \\
\text { Pronunciation } & \\
\end{array}$ \\
\hline 11-15 & Listening & Audio Visual Aids & $\begin{array}{l}\text { Links Share } \\
\text { WhatsApp }\end{array}$ & $\begin{array}{l}\text { on Listening } \\
\text { News }\end{array}$ & $\begin{array}{l}\text { BBC Understanding } \\
\text { Idea }\end{array}$ \\
\hline $16-20$ & Writing & Class Assignments & $\begin{array}{l}\text { WhatsApp } \\
\text { Assignment }\end{array}$ & Writing News & $\begin{array}{l}\text { Grammar, } \\
\text { Vocabulary, Quality } \\
\text { and Variety of } \\
\text { Sentence, } \\
\text { Organization of } \\
\text { Content, Spellings } \\
\end{array}$ \\
\hline 21-25 & $\begin{array}{l}\text { Analytical\& } \\
\text { Critical Skills }\end{array}$ & $\begin{array}{l}\text { Lectures, } \\
\text { Discussion }\end{array}$ & $\begin{array}{l}\text { WhatsApp } \\
\text { Discussions }\end{array}$ & \begin{tabular}{l|l} 
Group & Critical Analysis \\
Articles
\end{tabular} & \begin{tabular}{l|l} 
s of Analyzing \\
Problem \\
Reasoning
\end{tabular} \\
\hline
\end{tabular}

\section{ReSUlts}

Chart no. 1.2 shows the content validity of the written test constructed to evaluate the academic performance of students.



Chart no.1.2. (Percentage showing content validity of written test) Pretest to evaluate the skills of students before experiment:

Chart 1.3 shows the major difference between pretest and posttest of both traditional and digital Chaupal.

\section{Difference between pretest and posttest of Traditional and Digital Chaupal}

WhatsApp

$\begin{array}{ccccc}0 & 1 & 2 & 3 & 4 \\ & \text { Post } & \text { 口 Pre } & & \end{array}$

Chartno.1.3. (Pre-test and Posttest of both controlled and experimental groups) 
Power of "WhatsApp Chaupal" on the Academic Enactment of Graduate Students of Lahore- A Review Paper

The average score for each skill (reading, writing, speaking, listening, critical and analytical skills) by all students are mentioned below:

Table2. Scores of pretest and posttest of control and experimental group

\begin{tabular}{|c|c|c|c|c|}
\hline Students & $\begin{array}{l}\text { Before } 1^{\text {st }} \text { semester } \\
\text { classroom (out of } 20)\end{array}$ & $\begin{array}{l}\text { After } 1^{\text {st }} \text { semester } \\
- \text { classroom (out of 20) }\end{array}$ & $\begin{array}{l}\text { Before } 2^{\text {nd }} \text { semester } \\
\text { classroom }+ \text { WhatsApp } \\
\text { (out of } 20)\end{array}$ & $\begin{array}{l}\text { After } 2^{\text {nd }} \text { semester } \\
- \text { classroom }+ \text { WhatsApp } \\
\text { (out of } 20)\end{array}$ \\
\hline 01 & 10 & 12 & 9 & 13 \\
\hline 02 & 9 & 11 & 5 & 10 \\
\hline 03 & 3 & 5 & 4 & 11 \\
\hline 04 & 6 & 10 & 10 & 15 \\
\hline 05 & 2 & 3 & 5 & 8 \\
\hline 06 & 7 & 8 & 7 & 12 \\
\hline 07 & 3 & 5 & 6 & 10 \\
\hline 08 & 5 & 6 & 8 & 9 \\
\hline 09 & 7 & 5 & 5 & 6 \\
\hline 10 & 5 & 8 & 7 & 7 \\
\hline 11 & 3 & 4 & 10 & 10 \\
\hline 12 & 2 & 6 & 5 & 11 \\
\hline 13 & 7 & 9 & 6 & 12 \\
\hline 14 & 6 & 8 & 3 & 5 \\
\hline 15 & 3 & 6 & 5 & 11 \\
\hline 16 & 8 & 7 & 9 & 12 \\
\hline 17 & 3 & 5 & 2 & 11 \\
\hline 18 & 4 & 7 & 3 & 8 \\
\hline 19 & 8 & 11 & 5 & 7 \\
\hline 20 & 2 & 5 & 11 & 13 \\
\hline 21 & 6 & 6 & 5 & 6 \\
\hline 22 & 7 & 10 & 6 & 8 \\
\hline 23 & 3 & 5 & 7 & 8 \\
\hline 24 & 2 & 6 & 9 & 9 \\
\hline 25 & 7 & 10 & 5 & 7 \\
\hline Total & 161 & 178 & 157 & 238 \\
\hline Percentag & $32.2 \%$ & $35.6 \%$ & $31.4 \%$ & $47.6 \%$ \\
\hline
\end{tabular}

The low scores in the pretest determine that students didn't have sufficient knowledge about both subjects before getting enrolled in courses which can be considered as a limitation of the study. Though there might be other factors as well which may influence the findings. However, WhatsApp as a teaching tool acts as a main element in improving skills of students.

\subsection{Statistical Analysis Through SPSS}

The charts mentioned above shows a significant difference in the pretest and the posttest of students. T-test is appropriate when we want to compare the means of two samples. In order to check the validity of the posttest, $t$-test is used in this study. In order to check the validity of the findings, $t$-test is used in this study. The findings are mentioned below;

Table3. Comparison of scores after the session of Chaupal and Digital Chaupal

\begin{tabular}{|l|l|l|l|l|l|}
\hline & STUDENTS & $\mathrm{N}$ & Mean & Std. Deviation & Std. Error Mean \\
\hline SCORES & CLASSROOM & 25 & 7.12 & 2.455 & .491 \\
\hline & WHATSAPP & 25 & 9.56 & 2.551 & .510 \\
\hline
\end{tabular}

Table4. T-test for Equality of Means

\begin{tabular}{|l|l|l|l|l|l|}
\hline \multicolumn{2}{|l|}{ t-test for Equality of Means } \\
\hline
\end{tabular}


Findings conclude that those students who were taught in the classroom scored lower than the ones who were taught through WhatsApp. Since the p value is 0.001 (see Table 4) which is less than 0.05 , we can conclude that WhatsApp as a teaching tool can affect the academic grades/scores of students in a positive manner.

\section{DISCUSSION}

The findings show that students of digital Chaupal performed better than students of traditional Chaupal. It was noticed that teaching through WhatsApp group boosts confidence level and understanding among students. It was also observed that students were excited on digital Chaupal (WhatsApp group) as compared to traditional Chaupal (classroom session). They were reluctant to attend classroom session. However, they participated more actively on digital Chaupal and took a lot of interest in the ongoing discussions and debate. Jones, Edwards, and Reid (2009) discussed it in their research work that students use their smart phone on daily basis. Cetinkaya (2017) also asserted that students are willing to use WhatsApp for learning purpose and are of view that audio visual communication on WhatsApp helps them to learn things in bettermanner.

The significant difference in the scores of students after using WhatsApp group confirms the notion that WhatsApp can play a significant role in smoothening and strengthening the educational system of Pakistan. Rosenberg and Asterhan (2018) asserts the fact that it has become most popular avenue for communication related academic stuff.

The session of traditional Chaupal (face to face learning) was not much effective in improvingcreativeandcognitiveskillofstudentsasstudentswerealreadyfamiliarwiththesame classroom. They were not paying much attention in the class and took it as additional burden. Students were reluctant to attend class in the form of traditional Chaupal. They didn't participate much and so scored lower than the students of digital Chaupal.

However, learning on digital Chaupal was new experience for them. It provides them a platform where they can discuss their matters without any hesitation or time restriction. Furthermore, the ability to send video, audio message, video links and images helped them to understand the concept in better way. Preston et al. (2010) states that online lectures are more helpful in academic environment and students can easily learn from them. The same findings are supported by another researcher in which web based learning was considered most effective form of learning (Cheung, Hew, \& $\mathrm{Ng}$, 2008).

WhatsApp is also being used to circulate important messages. It's easy to share lectures on WhatsApp group as WhatsApp support .PPT files, videos, images. One can share important video or website links on WhatsApp. The findings are consistent with the findings of (Rosenberg \&Asterhan, 2018) in which it was discovered that WhatsApp is being used for both academic and organizational purpose.

It was observed that WhatsApp group participation was more convenient for students as compared to classroom learning. In that way students can communicate as per their schedule and convenience. The findings are in agreement with the findings of Rosenberg and Asterhan (2018). In their research work they listed easy access as one of the major advantage of using WhatsApp group for learning purpose. Kustijono and Zuhri (2018) also suggest that WhatsApp improves creative and thinking skills of students.

It was discovered that WhatsApp has so many features which can be utilized in academic scenario. First, students can avail the facility of learning at their doorsteps. Sometimes distance becomes a barrier and in case of absence one cannot access the notes or lecture. Findings show that it was easy for them to access notes through WhatsApp. Furthermore, different features of WhatsApp facilitate students better than the facilities available in classroom. For example, through the audio feature of WhatsApp students could easily ask their queries in detail at any time. The findings are consistent with the findings of Rahman and Stephen (2016) which shows that WhatsApp can also be used to improve the reading skills of students.

WhatsApp is also beneficial for professional development of teacher. It was easy for instructortounderstandthepersonalityandnatureofstudentsonWhatsApp.Fromateacher'spoint of view, it was quite helpful to create WhatsApp group with students in order to share notes and updates with them. It also creates a strong bond with students. Due to its fast-paced interaction, students were 
involved in sharing messages almost all the time. The flood of messages on WhatsApp group was sometimes disturbing and it was difficult to monitor the ongoing discussion. Rosenberg and Asterhan (2018) listed overload of communication as drawback of using WhatsApp as a teaching tool. However, it increased the understanding between teacher and students. WhatsApp plays an effective role in promoting healthy relationship between students and teacher (Hershkovitz, Elhija, \&Zedan, 2019).

The findings of this study indicated a significance difference between the pretest and the posttest which proves that the involvement of WhatsApp can make a significant difference in the academic grades of students. The findings are broadly consistent with previous studies (Barhoumi, 2015; Khan, Khan Malik, \& Amin, 2014; Minalla, 2018; Pratama\&Kartikawati, 2017). It was also observed that WhatsApp promote healthy peer to peer and peer to teacher discussion. Students can easily share links, videos and emoji to support their argument (Javid, Malik, \& Gujjar, 2011; Lin, 2012; O'Hara et al., 2014). The study is pertinent for future researchers to understand the importance of utilizing information communication and technology tools in academic institutes. Teachers can also use social media groups such as WhatsApp to improve dynamic skills of students. WhatsApp group ca also be used to discuss class lectures and assignments.

\section{CONCLUSION}

The purpose of the study was to evaluate the significance of digital Chaupal to improve academic grades and skills of students. Findings suggest that WhatsApp was supportive for students' cognitive skills. It further extended interpersonal connection between teacher and students. It further emerged as communities of practices. The study concludes that WhatsApp application is a pertinent tool in academic institutes which can improve academic performance of students. It can also enhance the vision and build the confidence of students. We can utilize this technology to engage students in order to develop their confidence and improve their cognitive and creative skills in academic sectors. Future researchers are advised to take diverse sample to examine the effects of using WhatsApp application in academic context on wider scale.

\section{REFERENCES}

[1] Ahad, A. D., \& Lim, S. M. A. (2014). Convenience or nuisance?: The 'WhatsApp' dilemma. ProcediaSocial and Behavioral Sciences, 155, 189-196.

[2] Amry, A. B. (2014). The impact ofwhatsapp mobile social learning on the achievement and attitudes of female students compared with face to face learning in the classroom. European Scientific Journal, ESJ, $10(22)$.

[3] Awada, G. (2016). Effect of WhatsApp on critique writing proficiency and perceptions toward learning.Cogent Education, 3(1), 1264173.

[4] Azeema, N., \&Nazuk, A. (2017). WhatsApp and Journalism: News Practices of Pakistani Journalists. Science, Technology and Development, 36(4), 249-258.

[5] Barhoumi, C. (2015). The Effectiveness of WhatsApp Mobile Learning Activities Guided by Activty Theory on Students' Knowldege Management. Contemporary Educational Technology, 6(3), 221-238.

[6] Bere, A. (2012). A comparative study of student experiences of ubiquitous learning via mobile devices and learner management systems at a South African university. Paper presented at the 2012Conference.

[7] Blabst, N., \&Diefenbach, S. (2017). WhatsApp and Wellbeing: A study on WhatsApp usage, communication quality and stress. Paper presented at the Proceedings of the 31st British Computer Society Human Computer Interaction Conference.

[8] Bouhnik, D., Deshen, M., \&Gan, R. (2014). WhatsApp goes to school: Mobile instant messaging between teachers and students. Journal of Information Technology Education: Research, 13(1), 217-231.

[9] Cetinkaya, L. (2017). The impact of WhatsApp use on success in education process.

[10] International Review of Research in Open and Distributed Learning, 18(7).

Citation: Mudassar Riaz Bhatti, et.al. "Power of "WhatsApp Chaupal" on the Academic Enactment of Graduate Students of Lahore- A Review Paper". International Journal of Media, Journalism and Mass Communications (IJMJMC), vol 6, no. 2, 2020, pp. 21-29 doi: http://dx.doi.org/10.20431/2454-9479.0602003.

Copyright: () 2020 Authors. This is an open-access article distributed under the terms of the Creative Commons Attribution License, which permits unrestricted use, distribution, and reproduction in any medium, provided the original author and source are credited. 